\title{
Gene Transfer Therapy: A Survey of Clinical Trials for Treatment of Various Cancers
}

\author{
Shruthi Selvaraj \\ M. S. Ramaiah Institute of Technology \\ Bangalore, India \\ shruthi.s.selvaraj@gmail.com
}

\section{Extended Abstract}

Gene therapy is emerging as a promising approach for treatment of cancers with minimal side effects compared to conventional chemotherapeutic treatments [1]. The trends in gene therapy treatment of cancers have been summarized in [1, 6]. Clinical trials are ongoing and many successful outcomes have been reported worldwide [2 - 7]. Gene transfer therapy is one of the three types of gene therapy for treatment of a variety of cancers. It is relatively a recent approach which introduces new genes into cancerous cells or the surrounding cancerous tissues to cause their death or to slow down their growth. While there are papers describing specific clinical trials of gene transfer therapy for treatment of cancers, the author did not find a comprehensive survey and review of the clinical trials of gene transfer therapy for treating various cancers. In order to address this gap, this paper surveys the clinical trials that have been undertaken till 2015 and summarizes the findings. The summaries that are provided in this paper include geographic distribution of the trials, indications addressed, vectors used, gene types transferred and the outcomes reported. Using relevant statistical tests on the number of clinical trials, papers published and the outcomes reported for each type of cancer, an attempt has been made to identify the types of cancers for which gene transfer therapy treatment is most commonly used.

\section{References}

[1] D. Cross and J. K. Burmester, Gene therapy for cancer treatment: past, present and future, Clinical medicine \& research, vol. 4, no. 3, pp. 218-227, 2006.

[2] M. L. Edelstein, M. R. Abedi, J. Wixon, and R. M. Edelstein, Gene therapy clinical trials worldwide 1989-2004an overview, The journal of gene medicine, vol. 6, no. 6, pp. 597-602, 2004.

[3] M. L. Edelstein, M. R. Abedi, and J. Wixon, Gene therapy clinical trials worldwide to 2007an update, The journal of gene medicine, vol. 9, no. 10, pp. 833-842, 2007.

[4] Journal of Gene Medicine. (2015, July). Gene Therapy Clinical Trials Worldwide. [Online]. Available: http://www.wiley.com/legacy/wileychi/genmed/clinical/.

[5] S. L. Ginn, I. E. Alexander, M. L. Edelstein, M. R. Abedi, and J. Wixon, Gene therapy clinical trials worldwide to 2012-an update, The journal of gene medicine, vol. 15, no. 2, pp. 65-77, 2013.

[6] J. A. Roth and R. J. Cristiano, Gene therapy for cancer: what have we done and where are we going?, Journal of the National Cancer Institute, vol. 89, no. 1, pp. 21-39, 1997.

[7] W. Walther and P. M. Schlag, Current status of gene therapy for cancer, Current opinion in oncology, vol. 25, no. 6, pp. 659-664, 2013. 